\title{
Economics
}

2017; 6(5): 51-57

http://www.sciencepublishinggroup.com/j/eco

doi: 10.11648/j.eco.20170605.11

ISSN: 2376-659X (Print); ISSN: 2376-6603 (Online)

\section{Evolutionary Game Analysis of Financial Regulation and Innovation Under Asymmetric Conditions}

\author{
Hua Jinliang \\ Shanghai Research Institute, Shanghai University, Shanghai, China \\ Email address : \\ 774198276@qq.com \\ To cite this article: \\ Hua Jinliang. Evolutionary Game Analysis of Financial Regulation and Innovation Under Asymmetric Conditions. Advances in Materials. \\ Vol. 6, No. 5, 2017, pp. 51-57. doi: 10.11648/j.eco.20170605.11
}

Received: August 17, 2017; Accepted: September 30, 2017; Published: November 7, 2017

\begin{abstract}
The loose financial supervision and excessive financial innovation will lead the country to heavy losses in financial crisis. So how to balance the relationship between financial supervision and financial innovation and make financial supervision and financial innovation to achieve complementary has become a hot issue. The financial supervision and financial institutions are a process of repeated game, but the research on them is still in a superficial stage. Therefore, this paper uses evolutionary game theory and method to analyze the dynamic replication system of asymmetric evolutionary game of two groups of financial institutions and regulators in China. And the evolutionary stable state of the system under different conditions is analyzed. The conclusion is that under different parameter values, the other side adopts different strategies, and the system will tend to different equilibrium states.
\end{abstract}

Keywords: Financial Innovation, Financial Regulation, Evolutionary Game

\section{Introduction and Literature Review}

In the era of economic globalization, financial innovation has gradually become the development of the main theme, but excessive financial innovation and loose financial supervision will lead to economic losses. Financial innovation can bring benefits while compliance management can reduce the risk. These two are contradictory unity, and the lack of any one will have a huge impact on the development of banks and social economy. At present, China's financial innovation is divided into seven categories: system innovation, product innovation, market innovation, institutional innovation, resource innovation, science and technology innovation and management innovation. Generally refers to the change of the existing financial system and the addition of new financial instruments to obtain the potential profits that the existing financial system and financial instruments can't obtain, which is a slow, continuous development process for profit motivation. China has great potential for financial innovation. In the future development, we should pay more attention to the relationship between financial innovation and financial supervision. Because this is related to how financial innovation and financial supervision promote each other, that is to say, how to improve the efficiency of supervision and guide the financial.

Since 1970s, one of the hot issues in the field of international financial theory was how to balance the relationship between financial innovation and financial regulation and their role in the evolution of each other. Different scholars have carried out different perspectives on this hot spot, research results could be roughly divided into two categories: the first category was that supervision and financial innovation was a causal relationship. For example, Bhattacharyya and Nanda (2000) found that financial regulation was a major incentive for investment banks to develop more new products [1]. Another, Liu yanping (2016) argued that the avoidance of financial regulation was an important factor in promoting financial innovation [2]. Zhang Meng (2017) believes that, according to the source of financial innovation, financial innovation was born in order to effectively avoid financial risks. Financial innovation has developed rapidly because of the existence of financial risks [3]. However, over time; many financial phenomena became difficult to explain, so the second types appeared. They thought that financial innovation and supervision were unity of opposites, and they promoted each other. Yin Long (2005) believed that on one hand financial supervision and financial innovation complemented each other, and standardized 
supervision is an institutional guarantee for innovation. On the other hand, vigorous innovation was an important way to save regulatory resources and to improve the efficiency of supervision [4]. Li Shusheng and Qi Jingyu (2008) believed that the relationship between the two was an interactive equilibrium process, which promoted each other in the interaction and mutual causation. Moreover, their dynamic changes made financial supervision work to be adjusted and changed. In addition, "Regulation, financial innovation, re-regulation, re-financial innovation", this process is not a simple repetition. Every new cycle has new starting points, which help to promote the reform and progress of the financial industry [5]. Liu yanyan (2014) analyzed the relationship of financial innovation and financial supervision on the formation of the shadow banking system based on the analysis of development and influence. Financial innovation is the driving force for the development of the financial industry, but the development of financial innovation can't be uncontrolled excessive development. At the same time, financial supervision should keep up with the pace of financial innovation and better serve the real economy [6]. Kim, Koo and Park (2013) in the subprime crisis as a starting point for the research on this problem, the results showed that there was a mismatch between financial supervision and financial innovation [7]. Cao Dong (2014) believe that financial innovation plays a decisive role in the development of the financial industry. Financial supervision has some influence on financial innovation. Only financial innovation and financial supervision can achieve real equilibrium among the two, and China's economy and financial market can develop healthily and sustainably[8]. Peng hongfeng (2016) believes that financial innovation and financial supervision are mutually related and dynamic [9].

Based on the above literature can be seen, scholars have conducted a lot of researches on financial supervision and financial innovation. The basic recognition of the relationship between financial innovation and financial supervision is a dynamic process, but there is no detailed study of the game process between them, and only stay on the surface. It is worth noting that most of the existing research frameworks are derived from the general game model, because they failed to fully consider the different situations of the relationship between the two and when the two are in a stable state. For example, Deng Yang (2015) through the construction of evolutionary game model, arranged the relationship between financial regulation and financial innovation, and gave improvement measures [10]. This paper is based on the idea of evolutionary game theory to study the financial supervision and financial institutions from the perspective of dynamic game process and research under different parameters in both steady states. And then compare the differences under different parameters and propose reasonable suggestions.

\section{Game Model Construction}

Do some explanations to the game model: first, financial regulators in this paper refers to the People's Bank Of China (PBOC), China Banking Regulatory Commission (CBRC), China Securities Regulatory Commission (CSRC) and China Insurance Regulatory Commission (CIRC). Another, financial innovation and financial supervision has the characteristics of long-term and continuous. So the game between financial innovation and financial supervision is a continuous and repetitive behavior. Besides, the information of financial institutions and financial regulators in the game is not completely symmetrical.

In each game, financial institutions have a certain probability to choose reasonable innovation strategy or excessive innovation strategy. Financial regulators have a certain probability to choose verification strategy or choose non verification strategy. Therefore, based on the social welfare perspective, we can get the model as shown in table 1:

Table 1. Model Tables of Financial Institutions and Financial Regulators.

Verification; reasonable innovation

Verification; excessive innovation

Non verification; reasonable innovation

Non verification; excessive innovation

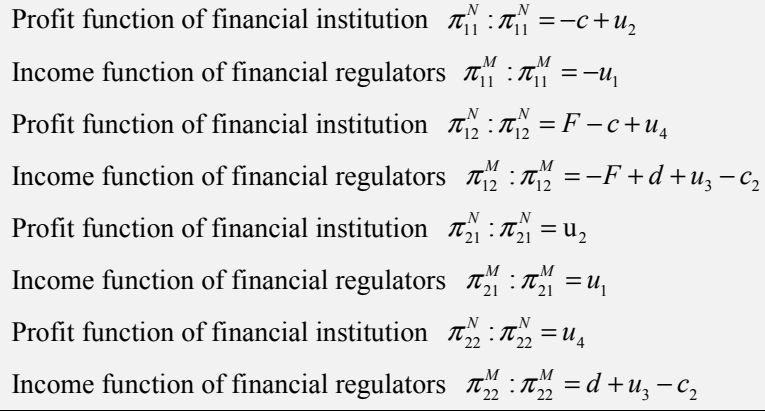

The symbols and instructions used in the model are shown in table 2:

Table 2. The Game Model of Financial Institutions and Financial Supervision Symbols and Explanations.

\begin{tabular}{lll}
\hline Game sides & symbols & Symbolic description \\
\hline \multirow{3}{*}{ Financial regulators } & $\mathrm{c}$ & Regulatory costs paid by financial regulators \\
& $\mathrm{u}_{2}$ & Gains gained by financial regulators in selecting verification strategies \\
& $\mathrm{u}_{4}$ & The gains received by financial regulators in choosing non checking strategies \\
Financial institution & $\mathrm{d}$ & Additional gains from financial institutions' excessive innovation \\
& $\mathrm{c}_{2}$ & Cost of excessive innovation payments by financial institutions \\
\hline
\end{tabular}




\begin{tabular}{lll}
\hline Game sides & symbols & Symbolic description \\
\hline & $\mathrm{u}_{1}$ & The social benefits of financial institutions' rational innovation \\
& $\mathrm{u}_{3}$ & Social benefits gained by financial institutions over innovating \\
$\mathrm{F}$ & The amount of money a financial institution has been penalized \\
\hline
\end{tabular}

Through the analysis of the four cases above, we could calculate the possible income size of financial institutions and financial regulators under different strategies. Then the income matrix of the game between the financial institution and the financial regulator is given in (Table 3 ).

Table 3. Profit Matrix of Game Between Financial Institutions and Financial Regulators.

\begin{tabular}{llll}
\hline \multirow{2}{*}{ types } & & financial institutions & \\
\cline { 2 - 4 } & & reasonable innovation:q & excessive innovation:1-q \\
\hline \multirow{2}{*}{ financial regulators } & Verification:p & $-\mathrm{c}+\mathrm{u}_{2} ; \mathrm{u}_{1}$ & $\mathrm{~F}-\mathrm{c}+\mathrm{u}_{4} ;-\mathrm{F}+\mathrm{d}+\mathrm{u}_{3}-\mathrm{c}_{2}$ \\
& Non verification: $1-\mathrm{p}$ & $\mathrm{u}_{2} ; \mathrm{u}_{1}$ & $\mathrm{u}_{4} ; \mathrm{d}+\mathrm{u}_{3}-\mathrm{c}_{2}$ \\
\hline
\end{tabular}

\section{Solutions and Analysis of Game Model Between Financial Innovation and Financial Supervision}

In this section, the choice of strategy between the financial institutions and the financial regulators in the game of bounded rationality will be analyzed. In the game between financial institutions and financial regulators, the probability that the financial supervision institution chooses the supervision and strategy is $p$, the probability of choosing the non-verification strategy is $1-p$; the concept of choosing the reasonable innovation strategy for the financial institution is $\mathrm{q}$, and the probability of selecting the excessive innovation strategy is $1-\mathrm{q}$.

For financial regulators:

The expected return of the financial regulator is:

$$
U_{11}=q \pi_{11}^{N}+(1-\mathrm{q}) \pi_{12}^{N}
$$

The expected return of non-regulatory financial institutions is:

$$
U_{12}=q \pi_{21}^{N}+(1-\mathrm{q}) \pi_{22}^{N}
$$

The average expected return of the financial regulator is:

$$
\bar{U}=p U_{11}+(1-p) U_{12}
$$

For financial institutions:

The expected benefit of rational innovation is:

$$
V_{11}=p \pi_{11}^{N}+(1-\mathrm{p}) \pi_{12}^{N}
$$

The expected benefit of excessive innovation is:

$$
V_{12}=p \pi_{21}^{N}+(1-\mathrm{p}) \pi_{22}^{N}
$$

The average expected return of financial institutions is:

$$
\bar{V}=q V_{11}+(1-q) V_{12}
$$

The replicator dynamics equation of financial regulator and the replicator dynamics equation of financial institutions can be obtained respectively according to the replicator dynamics of biological evolution:

$$
\begin{aligned}
& F(p)=d p / d t=p(1-p)\left[q\left(\pi_{11}^{N}-\pi_{21}^{N}\right)+(1-q)\left(\pi_{12}^{N}-\pi_{22}^{N}\right)\right] \\
& F(q)=d q / d t=q(1-q)\left[p\left(\pi_{11}^{M}-\pi_{12}^{M}\right)+(1-p)\left(\pi_{21}^{M}-\pi_{22}^{M}\right)\right]
\end{aligned}
$$

Where $F(p)$ indicates the rate of change of the probability of the financial regulatory agency's "verification" strategy, and $F(q)$ indicates the rate of change of the probability of the financial institution's choice of "reasonable innovation".

When equation (7) and equation (8) equal to zero, the stable state of financial supervision mechanism system can appear $\left(p_{1}=0, p_{2}=1, p_{3}=\frac{u_{1}-u_{3}-d+c_{2}}{-F}\right)$ and steady state of financial institutions system $\left(q_{1}=0, q_{2}=1, q_{3}=\frac{F-c}{F}\right)$. As a result, financial institutions and financial regulators can be combined to form a system in which 5 equilibrium points appear in the dynamic systems, respectively $(0,0),(0,1),(1$, $0),(1,1)$ and $\left(p^{*}, q^{*}\right)$. On this basis, Jacobian matrix is used to the full to judge whether 5 stable states of the two differential equation system is evolutionary stable strategy. The Jacobian matrix is as follows:

$$
J=\left[\begin{array}{cc}
\frac{\partial F(P)}{\partial P} & \frac{\partial F(P)}{\partial q} \\
\frac{\partial F(q)}{\partial P} & \frac{\partial F(q)}{\partial q}
\end{array}\right]
$$

Where

$$
\frac{\partial F(P)}{\partial P}=(1-2 P)[-\mathrm{cp}+(1-q)(F-c)]
$$

$$
\frac{\partial F(P)}{\partial q}=-p(1-p) F
$$




$$
\begin{gathered}
\frac{\partial F(\mathrm{q})}{\partial p}=q(1-q) F \\
\frac{\partial F(q)}{\partial q}=(1-2 q)\left[-p\left(u_{1}+F-c_{2}-u_{3}+d\right)+(1-p)\left(u_{1}-c_{2}-u_{3}+d\right)\right.
\end{gathered}
$$

The specific value of the Jacobian matrix in steady state is shown in table 4:

Table 4. The Specific Value of the Jacobian Matrix.

\begin{tabular}{lllll}
\hline stable state & $\frac{\partial \mathrm{F}(\mathrm{p})}{\partial \mathrm{p}}$ & $\frac{\partial \mathrm{F}(\mathrm{p})}{\partial \mathrm{q}}$ & $\frac{\partial \mathrm{F}(\mathrm{q})}{\partial \mathrm{p}}$ & $\frac{\partial \mathrm{F}(\mathrm{q})}{\partial \mathrm{q}}$ \\
\hline$(0,0)$ & $F-c$ & 0 & 0 & 0 \\
$(0,1)$ & $-\mathrm{c}$ & 0 & 0 & $\mathrm{u}_{1}-\mathrm{d}-\mathrm{u}_{3}+\mathrm{c}_{2}$ \\
$(1,0)$ & $\mathrm{c}-\mathrm{F}$ & 0 & 0 & $-\mathrm{u}_{1}+\mathrm{d}+\mathrm{u}_{3}-\mathrm{c}_{2}$ \\
$(1,1)$ & $\mathrm{c}$ & 0 & 0 & $\mathrm{u}_{1}+\mathrm{F}-\mathrm{d}-\mathrm{u}_{3}+\mathrm{c}_{2}$ \\
$\left(\mathrm{p} * \mathrm{q}^{*}\right)$ & 0 & $\mathrm{p}^{*}$ & $\mathrm{q}^{*}$ & 0 \\
\hline
\end{tabular}

where $P^{*}=\frac{u_{1}-d-u_{3}+c_{2}}{-F}, q^{*}=\frac{F-c}{F}$ from the Table 4 we know, the stable state $\left(\mathrm{p}^{*}, \mathrm{q}^{*}\right)$ corresponding with the trace of the Jacobi matrix is 0 , so that the stable state cannot be the ESS of the system, and only the other stable points are considered.

When $\Delta A=F-c, \Delta B=u_{1}-d-u_{3}+c_{2}, \quad \Delta C=-d-u_{3}+u_{1}+F+c_{2}$. The $\Delta A$ represents the social benefits difference between financial regulators check or not in financial institutions with excessive innovation, $\Delta B$ explains social income difference between financial institutions with excessive innovation and reasonable innovation in financial supervision institutions without verification, $\Delta C$ is social income difference between financial institutions with excessive innovation and reasonable innovation in financial supervision institutions with verification.

Situation one: $\Delta A>0, \Delta B>0, \Delta C>0$

In this situation: (1) In the case of excessive innovation in financial institutions, the benefit that the financial regulator with verification is greater than no-verification; (2) In financial institutions without verification, financial institutions with reasonable innovation benefit more than that of excessive innovation; (3) In financial institutions with verification, benefit of financial institutions with excessive innovation is more than that of reasonable innovation. At this point, the stability of the 4 steady states of the system is shown in table 5 .

Table 5. $\Delta A>0, \Delta B>0, \Delta C>0$ Stability Analysis of Steady State.

\begin{tabular}{llll}
\hline $\begin{array}{l}\text { Equilibrium } \\
\text { point }\end{array}$ & $\begin{array}{l}\text { Determinant } \\
\text { symbol of } \mathbf{J}\end{array}$ & $\begin{array}{l}\text { Trace symbol } \\
\text { of } \mathbf{J}\end{array}$ & Result \\
\hline $\mathrm{p}=0, \mathrm{q}=0$ & + & + & Unstable point \\
$\mathrm{p}=0, \mathrm{q}=1$ & + & - & ESS \\
$\mathrm{p}=1, \mathrm{q}=0$ & - & Uncertain & saddle point \\
$\mathrm{p}=1, \mathrm{q}=1$ & - & Uncertain & saddle point \\
\hline
\end{tabular}

As is shown in table $5,(0,1)$ is the system of evolutionary stability strategy. That is, financial regulators tend to non-verification, and financial institutions tend to rational innovation. When the market is in a state of integrity, for financial institutions no matter how financial regulatory agencies to take measures, rational innovation benefits are greater than the excessive innovation's. So the rational innovation is the best choice for financial institutions. Financial regulators are also not worried about excessive innovation in financial institutions.

Situation two: $\Delta A>0, \Delta B<0, \Delta C<0$

In this situation: (1) In the case of excessive innovation in financial institutions, the benefit that the financial regulator with verification is greater than no-verification; (2) In financial institutions without verification, financial institutions with reasonable innovation benefit less than that of excessive innovation; (3) In the case of financial regulatory verification, the benefits of financial institutions' rational innovation are less than the benefits of excessive innovation. At this point, the stability of the 4 steady states of the system is shown in table 6 .

Table 6. $\Delta A>0, \Delta B<0, \Delta C<0$ Stability Analysis of System Steady State.

\begin{tabular}{llll}
\hline $\begin{array}{l}\text { Equilibrium } \\
\text { point }\end{array}$ & $\begin{array}{l}\text { Determinant } \\
\text { symbol of } \mathbf{J}\end{array}$ & $\begin{array}{l}\text { Trace symbol of } \\
\mathbf{J}\end{array}$ & Result \\
\hline $\mathrm{p}=0, \mathrm{q}=0$ & - & Uncertain & saddle point \\
$\mathrm{p}=0, \mathrm{q}=1$ & - & Uncertain & saddle point \\
$\mathrm{p}=1, \mathrm{q}=0$ & + & - & ESS \\
$\mathrm{p}=1, \mathrm{q}=1$ & + & + & Unstable point \\
\hline
\end{tabular}

From table 6 analysis, $(1,0)$ is the evolutionary stability strategy of system. That is, financial regulators tend to verification, and financial institutions tend to excessive innovation. For this reason, financial regulators need to continue to increase incentives to increase their enthusiasm. As far as financial institutions are concerned, regardless of the measures taken by financial regulators, the benefits of excessive innovation are more than the benefits of rational innovation. Therefore, excessive innovation is the best choice for financial institutions.

Situation three: $\Delta A>0, \Delta B<0, \Delta C>0$

In this situation:(1) In the case of excessive innovation in financial institutions, the benefit that the financial regulator with verification is greater than no-verification; (2) In financial institutions without verification, financial institutions with reasonable innovation benefit less than that of excessive innovation; (3) In financial institutions with verification, benefit of financial institutions with reasonable innovation is more than that of excessive innovation. At this 
point, the stability of the 4 steady states of the system is shown in table 7.

Table 7. $\Delta A>0, \Delta B<0, \Delta C>0$ Stability Analysis of System Steady State.

\begin{tabular}{llll}
\hline Equilibrium point & $\begin{array}{l}\text { Determinant } \\
\text { symbol of } \mathbf{J}\end{array}$ & $\begin{array}{l}\text { Trace symbol } \\
\text { of } \mathbf{J}\end{array}$ & Result \\
\hline $\mathrm{p}=0, \mathrm{q}=0$ & - & Uncertain & saddle point \\
$\mathrm{p}=0, \mathrm{q}=1$ & - & Uncertain & saddle point \\
$\mathrm{p}=1, \mathrm{q}=0$ & - & Uncertain & saddle point \\
$\mathrm{p}=1, \mathrm{q}=1$ & - & Uncertain & saddle point \\
\hline
\end{tabular}

Drawn from the analysis of table 7 , in this case, the evolutionary stable strategy stable strategy is not all of the system. It shows that the two groups of financial supervision institutions and financial institutions cannot tend to a stable point, and the whole system is in a long period oscillation state.

Situation four: $\Delta A<0, \Delta B>0, \Delta C>0$

This situation said: (1) In the case of excessive innovation in financial institutions, the financial regulator's choice of verification proceeds less than the proceeds of non-selective verification; (2) In financial institutions without verification, financial institutions with reasonable innovation benefit more than that of excessive innovation; (3) In financial institutions with verification, benefit of financial institutions with reasonable innovation is more than that of excessive innovation. At this point, the stability of the 4 steady states of the system is shown in table 8 .

Table 8. $\Delta A<0, \Delta B>0, \Delta C>0 \quad$ Stability Analysis of System Steady State.

\begin{tabular}{llll}
\hline $\begin{array}{l}\text { Equilibrium } \\
\text { point }\end{array}$ & $\begin{array}{l}\text { Determinant } \\
\text { symbol of } \mathbf{J}\end{array}$ & $\begin{array}{l}\text { Trace symbol } \\
\text { of } \mathbf{J}\end{array}$ & Result \\
\hline $\mathrm{p}=0, \mathrm{q}=0$ & - & Uncertain & saddle point \\
$\mathrm{p}=0, \mathrm{q}=1$ & + & - & ESS \\
$\mathrm{p}=1, \mathrm{q}=0$ & + & + & Unstable point \\
$\mathrm{p}=1, \mathrm{q}=1$ & - & Uncertain & saddle point \\
\hline
\end{tabular}

From table 8 analysis, $(0,1)$ is the system of evolutionary stability strategy. That is, financial regulators tend to non-verification, and financial institutions tend to rational innovation. However, financial regulators need more and more incentive measures to prevent financial institutions from excessive innovation, and financial regulators are not in the state of verification.

Situation five: $\Delta A<0, \Delta B<0, \Delta C>0$

This situation said: (1) In the case of excessive innovation in financial institutions, the financial regulator's choice of verification proceeds less than the proceeds of non-selective verification; (2) In financial institutions without verification, financial institutions with reasonable innovation benefit less than that of excessive innovation; (3) In financial institutions with verification, benefit of financial institutions with reasonable innovation is more than that of excessive innovation. At this point, the stability of the 4 steady states of the system is shown in table 9 .
Table 9. $\Delta A<0, \Delta B<0, \Delta C>0 \quad$ Stability Analysis of System Steady State.

\begin{tabular}{llll}
\hline Equilibrium point & $\begin{array}{l}\text { Determinant } \\
\text { symbol of } \mathbf{J}\end{array}$ & $\begin{array}{l}\text { Trace symbol } \\
\text { of } \mathbf{J}\end{array}$ & Result \\
\hline $\mathrm{p}=0, \mathrm{q}=0$ & + & - & ESS \\
$\mathrm{p}=0, \mathrm{q}=1$ & - & Uncertain & saddle point \\
$\mathrm{p}=1, \mathrm{q}=0$ & + & + & Unstable point \\
$\mathrm{p}=1, \mathrm{q}=1$ & - & Uncertain & saddle point \\
\hline
\end{tabular}

From table 9 analysis, $(0,0)$ is the system of evolutionary stability strategy. That is, financial regulators tend to non-verification; financial institutions tend to excessive innovation. At this point, the market is in a state of bad faith. Financial institutions have no integrity, and depending on the intensity of financial supervision. At this point, financial regulators need to take verification measures to crack down on excessive innovation.

Situation six: $\Delta A<0, \Delta B<0, \Delta C<0$

This situation said: (1) In the case of excessive innovation in financial institutions, the financial regulator's choice of verification proceeds less than the proceeds of non-selective verification; (2) In financial institutions without verification, financial institutions with reasonable innovation benefit less than that of excessive innovation; (3) In the case of financial regulatory verification, the benefits of financial institutions' rational innovation are less than the benefits of excessive innovation. At this point, the stability of the 4 steady states of the system is shown in table 10 .

Table 10. $\Delta A<0, \Delta B>0, \Delta C>0$ Stability Analysis of System Steady State.

\begin{tabular}{llll}
\hline $\begin{array}{l}\text { Equilibrium } \\
\text { point }\end{array}$ & $\begin{array}{l}\text { Determinant } \\
\text { symbol of } \mathbf{J}\end{array}$ & $\begin{array}{l}\text { Trace symbol } \\
\text { of } \mathbf{J}\end{array}$ & Result \\
\hline $\mathrm{p}=0, \mathrm{q}=0$ & + & - & ESS \\
$\mathrm{p}=0, \mathrm{q}=1$ & - & Uncertain & saddle point \\
$\mathrm{p}=1, \mathrm{q}=0$ & - & Uncertain & saddle point \\
$\mathrm{p}=1, \mathrm{q}=1$ & + & + & Unstable point \\
\hline
\end{tabular}

From table 10 analysis, $(0,0)$ is still the system of evolutionary stability strategy. That is, financial regulators tend to non-verification; financial institutions tend to excessive innovation. At this point, no matter what measures financial regulators take, financial institutions will adopt excessive innovation strategy. The evolutionary stability strategy is the worst one at this point.

\section{Conclusions}

The equilibrium of financial regulators and financial institutions is decided by the game sides. In the case of asymmetry, both sides have different strategies. In the process of repeated game, the two sides continue improvement. In this paper, the evolutionary stability of system stability under 5 conditions is analyzed by classification. The analysis of the conditions of the 5 different parameters and the influence of the stability strategy of the system evolution are summarized as shown in table 11 . 
Table 11. Influence of Related Decision Parameters on Stability Strategy of System Evolution.

\begin{tabular}{ll}
\hline Condition & ESS \\
\hline$F>c, u_{1}>c_{2}+u_{3}-d, u_{1}>-F+c_{2}+u_{3}-d$ & $(0,1)$ \\
Or $F<c, u_{1}>c_{2}+u_{3}-d, u_{1}>-F+c_{2}+u_{3}-d$ & \\
$F>c, u_{1}<c_{2}+u_{3}-d, u_{1}<-F+c_{2}+u_{3}-d$ & $(1,0)$ \\
$F<c, u_{1}<c_{2}+u_{3}-d, u_{1}>-F+c_{2}+u_{3}-d$ & $(0,0)$ \\
Or $F<c, u_{1}<c_{2}+u_{3}-d, u_{1}<-F+c_{2}+u_{3}-d$ & \\
\hline
\end{tabular}

The following conclusions can be obtained by 5 kinds of evolutionary stable strategies under different conditions and parameters in table 11:

1. In the game between the financial institutions and the financial supervision institutions, the main factors that determine the strategy of the financial regulatory institutions are the costs of checking and the amount of fines to be used to detect excessive innovation of financial institutions. When the standard of punishment established by the financial regulatory institution is greater than the cost, whether the financial institutions' excessive innovation gains greater than the benefits of reasonable innovation determines whether the financial regulatory agency conducts verification. When the penalties set by the financial regulators are less than the cost. Whether the financial institutions' over innovation gains greater than the revenue from reasonable innovation will not affect the strategy of financial regulators.

2. In the game between the financial institutions and the financial supervision institutions. The strategic choice of financial institutions is mainly affected by the size of the benefits of excessive innovation and the intensity of punishment. When excessive innovation gains additional benefits more than punishment, financial institutions will choose excessive innovation strategies in order to obtain high profits. When excessive innovation gains additional benefits less than the punishment, financial institutions will choose reasonable innovation. The probability of financial institutions to choose excessive innovation increases with the increase of income. In order to maximize their own interests, the selection strategy of the financial institutions is mainly affected by the income. As long as the income is large enough, financial institutions will ignore social responsibility and turn to excessive innovation [11].

\section{Suggestions}

1. Strengthen financial supervision and improve the efficiency of financial supervision

To promote the implementation of the new regulatory standard and the optimization of regulatory tools and regulatory indicators system is the focus of financial regulators need to pay attention to. We should actively and steadily push ahead with the implementation of the new regulatory standards and optimize the regulatory tools and regulatory indicators. We will continue to implement the policy of dynamic capital adequacy, improve the control efficiency of the leverage level of capital adequacy, and strengthen the supervision of the liquidity risk. We will strengthen the financial institutions to shareholders and improve the net capital as the core risk control index system. Improving the regulatory mechanism and information sharing mechanism between financial regulators, and realize the standardization of information sharing between financial regulators and macroscopic departments [12]. For financial institutions to further refine the classification standard to achieve the control of regulatory arbitrage and the lack of supervision to fill.

2. Moderately increase financial innovation and guide financial institutions to make rational innovations

At present, the development of China's financial system is not perfect, and the development level of financial marketization is not high. Although there is no so serious excessive financial innovation and lack of supervision as shown in developed country, the financial innovation in China lags behind the developed countries. Regardless of the level of development of the financial market, and the type and level of financial products, which results in a lot of demand for financial services companies not satisfied. It can be said the financial industry in promoting the development of economy has not fully played its role. So at the same time in strengthening financial supervision and prevent financial risks We should increasing efforts to promote financial innovation, and accelerate the pace of financial reform. We will distribute more financial services products suitable for the need of economic development of our country, which contributes to meet the financial needs of consumers and give full play to the promotion of financial market to the development of real economy.

3. Promote balanced development of financial innovation and financial supervision.

From the history of foreign financial industry for many years to see, only financial innovation and financial supervision coordinate can achieve the prosperity of the development of financial market. Therefore, we should spare no effort to promote the balanced development of financial innovation and financial supervision. Continuing to expand the financial product innovation and business scope of sovereignty and streamline the approval process for innovative products and services. We should carry out financial innovation and financial supervision pilot work, which not only can be a good solution to the reporting and approval of some difficult issues, but also accumulate experience for the improvement of financial regulatory laws and regulations. We should further improve the legal and legal systems related to financial innovation and financial supervision. We should respect the law of market development and changing the concept and model of financial supervision, so that financial supervision could become a powerful guarantee for the development of financial markets.

\section{References}

[1] Bhattacharyya and Nanda, "Client discretion, switching costs, and financial innovation," Review of Financial Studies, vol. 13, no. 4, pp. 1101-1102, 2000. 
[2] Liu yanping, "Game analysis of legal system of financial innovation and financial supervision," northern trade and economic cooperation, no.7, pp. 115-116, 2016.

[3] Zhang Meng, "research on financial innovation and risk supervision in the background of post financial crisis," financial forum, no.9, pp. 93-94, 2017.

[4] Yin Long, "Development of financial innovation theory and evolution of financial supervision system," finance research, no.3, pp. 12-13, 2005.

[5] Li shusheng and Qi jingyu, "See the dialectical relationship between financial innovation and financial supervision from the US subprime mortgage crisis," Research on economics and management, no.7, pp.13-15, 2008.

[6] Liu yanyan, "Financial innovation and financial regulation: from the perspective of shadow banking," financial management, no.3, pp. 47-49, 2014.

[7] Kim T, Koo B and Park M, "Role of financial regulation and innovation in the financial crisis," Journal of Financial Stability, vol. 9, no. 4, pp. 662-672, 2013.
[8] Cao Dong, CaoWei and Wu junlong, "Game Study on financial innovation and supervision in the Internet era," Journal of Southeast University, no. 7, pp. 63-68, 2014.

[9] Peng hongfeng and Yang liuming, "Research on the relationship between financial innovation and incentive regulation based on Evolutionary Game," Journal of central finance and Economics, no. 9, pp. 36-38, 2016.

[10] Deng Yang, "Game Analysis of financial supervision and financial innovation in the post financial crisis era, finance and taxation, no. 1, pp. 41-43, 2015.

[11] Zhang zhiyuan, "Game Study on financial supervision and financial risk in the post financial crisis era," Beijing: Economic Science Press, 2015.

[12] Yu guanghe, "A study of the relationship between financial innovation and financial supervision -- an analysis based on Information Economics,” no. 9, pp. 35-37, 2011. 